\title{
DIMINUINDO O PRECONCEITO INDÍGENA LEVANDO AS VOZES INDÍGENAS: ANÁLISE LIVRO “QUANDO EU CAÇAVA TATU E OUTROS BICHOS"
}

\author{
Otávio Barduzzi Rodrigues da Costa ${ }^{1}$ \\ Tiago de Oliveira ${ }^{2}$
}

\begin{abstract}
RESUMO: O preconceito racial indígena é ainda um problema na sociedade e, portanto, na educação do Brasil. A desconstrução do preconceito através de várias a práticas inclusive escolares deve ser feita desde muito cedo para que o Brasil alcance um padrão mínimo de cidadania e inclusão. Apesar de existir uma lei que determina a temática em aula ainda é um tema muito pouco explorado na educação fundamental, ficando a cargo apenas do professor do ensino médio muitas vezes apenas na aula de sociologia tentar desconstruir preconceitos, mas nessa idade preconceitos já estariam naturalizados e enraizados na cultura do aluno. Cabe iniciar a desconstrução desde a educação infantil. A intenção deste estudo é apontar uma problemática ainda muito comum no ensino infantil. Acreditamos que trazendo a voz indígena para dentro da sala de aula, através de um livro de um educador indígena esse preconceito diminua.
\end{abstract}

Palavras-chave: Preconceito. Educação. Povos indígenas.

ABSTRACT: Indigenous racial prejudice is still a problem in society and, therefore, in education in Brazil. The deconstruction of prejudice through various practices, including school ones, must be done from a very early age so that Brazil reaches a minimum standard of citizenship and inclusion. Although there is a law that determines the theme in the classroom, it is still a very little explored theme in elementary education, leaving only the high school teacher in charge, often only in the sociology class, to try to deconstruct prejudices, but at this age prejudices would already be naturalized and rooted in the student's culture. It is necessary to start the deconstruction from early childhood education. The intention of this study is to point out a problem that is still very common in early childhood education. We believe that by bringing the indigenous voice into the classroom, through a book by an indigenous educator, this prejudice will be reduced.

Keywords: Prejudice. Education. Indigenous peoples.

'Doutorando em Educação, arte e História da Cultura pela Mackenzie. Mestre em filosofia pela Universidade Estadual Paulista Júlio de Mesquita Filho, licenciado em filosofia com especialização em filosofia e educação pela Uniclaretianas, Licenciado em pedagogia pela FACOL. Graduação em Ciências Sociais pela Universidade Estadual Paulista Júlio de Mesquita Filho (200o) com ênfase em antropologia. Bacharel em Direito pela ITE-Bauru -Advogado no OAB-SP 314.526 atuante em direitos humanos e do trabalho, Mestre em filosofia pela Universidade Estadual Paulista Júlio de Mesquita Filho, licenciado em filosofia com especialização em filosofia e educação pela Uniclaretianas, Licenciado em pedagogia pela FACOL.

2 Mestrando em Antropologia Social pela Faculdade de Filosofia, Letras e Ciências Humanas (FFLCH)- USP. Formado em pedagogia intercultural indígena, pedagogia "convencional", especialista em antropologia. E-mail: joebarduzzi@yahoo.com.br 


\section{INTRODUÇÃO}

Pretende-se com esse trabalho analisar a partir de um livro, aparentemente infantil de autoria indígena, a memória das lutas e a proposição de situações educacionais no ensino de cultura indígena.

O livro Quando eu caçava tatu e outros bichos, de Tiago Oliveira, ou melhor, Tiago Nhandewa, pedagogo e doutorando em Antropologia Social na USP não é um mero livro infantil, e sim um documento de memória indígena e que pode cooperar para certos problemas no que se refere a educação da memória indígena. O livro registra contos e memórias de aventuras de meninos indígenas. As histórias se passam em um determinado tempo e realidade nas aldeias onde autor mora e passou a sua infância. Um dos grandes objetivos é dar destaque à literatura indígena e incentivar a leitura e escrita nas escolas das aldeias indígenas de todo o País. A obra também procura quebrar estereótipos relacionados à cultura indígena.

O livro deixa de ser mera literatura infantil e passa a ser um documento de memória étnica pleno e com potencial para descontruir preconceitos sobretudo no âmbito escolar. O preconceito racial com afrodescendentes e indígena é parte integrante e horrível da cultura e história brasileira que infelizmente não foi superada. Apesar da ciência e do simples bom senso provar que não há razão para o racismo ele insiste em permanecer em pleno século 2ı. O que fazer para que ele diminua? Com certeza a educação tem um papel preponderante. É necessário desde muito cedo tentar desconstruir o preconceito. Um dos caminhos é trabalhar a realidade brasileira que se constitui profundamente enraizada na história e cultura afro-indígena.

Promover e ensinar a História e Cultura indígena não é mais (BRASIL, 1996) uma questão de vontade pessoal. É uma questão curricular de caráter obrigatório que envolve as diferentes comunidades: escola, família, e sociedade baseada na Lei no ${ }^{\prime}$ Io.172 e LDB visa fazer um resgate histórico para que os alunos conheçam um pouco mais o Brasil e melhor a sua própria história.

O que se tem observado na maioria das vezes são esforços isolados de alguns professores incluírem nas atividades pedagógicas assuntos que valorizem o conhecimento de História indigena junto aos alunos e a escola. No entanto, muitas vezes, a própria instituição não está engajada para promover o ensino voltado para a 
diminuição das desigualdades étnico-raciais. $\mathrm{Na}$ escola, sobretudo nos níveis elementares, grande parte do ensino se restringe a propagação de quase sempre uma forma de manter estereótipos apenas na semana do dia i9 de abril (BICALHO, 2018).

Uma solução e trazer as vozes indígenas para dentro da sala de aula. Assim uma proposta para desconstrução do preconceito é usar documentos de autoria indígena que não tenham medo de problematizar as situações. Eles estão vivos, tem voz e podem falar per-si. Excluir o indígena do processo educacional só mantem os estereótipos e preconceitos. O livro chega como potencial de uso tanto em sala de aula como em formação de professores. Pretende-se então propor uma temática que visa minorar o preconceito contra indígenas discutindo no âmbito do presente congresso suas potencialidades.

O preconceito racial e indígena é parte integrante e horrível da cultura e história brasileira que infelizmente não foi superada. O Brasil já começa como uma máquina de moer gente. Apesar da ciência e do simples bom senso já provar que não há razão para o racismo ele insiste em permanecer em pleno século 2I. O que fazer para que ele diminua? Os caminhos são vários, envolvem desde comunicação, conscientização de rua, mas com certeza a educação tem um papel preponderante.

No entanto a literatura pode se aliar a educação e alcançar amis pessoas no intuito de minorar o preconceito. É necessário desde muito cedo tentar desconstruir o preconceito, uma vez que fica mais difícil quando esse se naturaliza nas opiniões. Cabe ao ensino em toda sua jornada, desde o ensino infantil até a faculdade e até mesmo durante todo o processo de vivência educar para a cidadania e, portanto, para minorar o preconceito. Um dos caminhos é trabalhar a realidade brasileira que se constitui profundamente enraizada na história e cultura afro-indígena e mostrar que de certo modo todos somos um e que não há motivos para diferença. Preconceito é definido pelo sociólogo Nogueira como:

\footnotetext{
Considera-se como preconceito racial uma disposição (ou atitude) desfavorável, culturalmente condicionada, em relação aos membros de uma população, aos quais se têm como estigmatizados, seja devido à aparência, seja devido a toda ou parte da ascendência étnica que se lhes atribui ou reconhece.. (NOGUEIRA, 1985, p. 78-9)
}

A legislação que combate o racismo na escola prevê ainda, na tentativa de amenizar os preconceitos em sala de aula propõe-se que não sejam abordados nas 
escolas certos temas como: raça, racismo, etnia, etnocentrismo, discriminação racial, etc. apesar da lei pouco ou nada no ensino fundamental tem sido feito de efetivo como técnica para aplicação dessa lei que envolve a cidadania(LIMA, 2006), ficando a cargo apenas do professor do ensino médio, muitas vezes apenas na aula de sociologia tentar desconstruir preconceitos, mas nessa idade preconceitos já estariam naturalizados e enraizados na cultura do aluno. Através de entrevistas semi-estruturada e pesquisa bibliográfica o presente trabalho se propõe a apontar certos problemas e propor soluções sala da aula para se trabalhar tão importante conteúdo.

\section{A IMPORTÂNCIA DA FORMAÇÃO E PREPARO DOS PROFESSORES}

O dualismo se define pela diferença educacional daqueles que tem acesso a bens culturais daqueles que não tem este acesso. Existe então uma diferença escolar uma escola para aqueles que podem ter acesso aos bem culturais e aqueles que não têm. $O$ dualismo na educação brasileira se firma na própria história brasileira. Ao organizarse a sociedade colonial, as benesses da educação e cultura eram apenas dadas a classe dominante. As reformas da educação para todos apesar de multiplicar aceso a educação essa constituiu-se de forma dual, enquanto que os mais ricos tinham escolas melhores os mais pobres ficaram com pior qualidade de ensino. Libaneo define:

O dualismo da escola brasileira em que, num extremo, estaria a escola assentada no conhecimento, na aprendizagem e nas tecnologias, voltada aos filhos dos ricos, e, em outro, a escola do acolhimento social, da integração social, voltada aos pobres e dedicada, primordialmente, a missões sociais de assistência e apoio às crianças. (LIBANEO, 2012. p . 16)

No entanto engana-se quem pensa que o dualismo ficou restrito às fases inferiores e técnicas de ensino. No ensino superior também há o dualismo no ensino superior. Embora louvável e de certo modo positivo, nos últimos anos multiplicou-se o acesso a educação superior brasileira. Porém também se multiplicaram as faculdades sem qualquer qualidade.

O número estrondoso de IES (instituições de ensino superior) particulares se multiplicou por quase 20 vezes na última década. Porém não foi acompanhado de aumento da qualidade. A pesquisa no INEP(INEP-2oII - dados em http://inepdata.inep.gov.br/analytics/saw.dll? Dashboard) mostra que o números de IES privadas cresceu mais de 20 vezes. A pesquisa de Leda e Mancebo (2009) já 
demonstrou que apenas ouve uma preocupação em aumentar o ensino superior sem que esse fosse devidamente fiscalizado. A situação piora pela multiplicação desenfreada de cursos EaD sem qualquer qualificação. Enquanto as IES de referência sucateamento as públicas passam por um processo de elitização e sucateamento, as privadas são acesso de pessoas mais pobres, porém não há interesse na qualidade(QUARESMA,200o), visto que a maioria absoluta das IES particulares visam o lucro causa do dualismo e da má qualidade de ensino.

A escola que busca lucro e não ciência é produto da estrutura capitalista e tende a multiplicar a má educação visto que é produto do capitalismo e se tendo o lucro como base, não tende a investir em pesquisa e formação e sim apenas se tornar fabrica de diplomas. O dualismo no sistema capitalista de fabricar diplomas se manifesta como de destinação de mercado apenas para ter o mínimo de conhecimento necessário aos sistemas de produção e de reprodução das divisões de classes. (SOUZA \& SILVA, 2003). Assim também o é no ensino superior. Como o ensino superior, e a maioria das IES só buscam o lucro acaba investindo em professores sem formação, poça biblioteca e sem laboratórios e outros recursos. O resultado como também demonstrado por Gatti (2010) é um crescente exército de professores despreparados em especial na pedagogia.

Os professores, que em sua formação não receberam preparo especial para o ensino da cultura africana e suas reais influências para a formação da identidade do nosso país, entram em conflito quanto à melhor maneira de trabalhar essa temática na escola. Nesse sentido, este ponto pode ser um dos obstáculos estabelecidos com a legislação, porque nessa lei não há nenhuma menção de cursos para capacitação dos professores ou ainda a reestruturação das bases pedagógicas num movimento que resgate e ressalte a importância dessa cultura em sala de aula. Sendo assim, é primordial a preparação desses professores, principalmente os do ensino infantil onde se inicia o desenvolvimento humano e social das crianças; porque é durante a educação infantil que as crianças já começam a conhecer seu corpo, as diferenças e semelhanças entre os colegas do grupo escolhem com quem brincar e se relacionar na escola, tem suas preferências por brinquedos, e, no entanto é fundamental que o educador trabalhe em sala de aula questões sobre diferença e em especial as relacionadas as diferenças raciais, não só com as crianças, mas com as famílias e comunidade. 
O que se tem observado na maioria das vezes são esforços isolados de alguns professores incluírem nas atividades pedagógicas assuntos que valorizem o conhecimento de História da África junto aos alunos e a escola. No entanto, muitas vezes, a própria instituição não está engajada para promover o ensino voltado para a diminuição das desigualdades étnico-raciais.

Muitas vezes o assunto tratado de forma mecânica. Ao entrevistar muitas professoras oriundas de universidades $\mathrm{EaD}$, no interior de São Paulo, ao serem perguntados como tratavam a temática indígena e negra na sala de aula era a parecida com uma resposta exemplo que ora se seleciona: "as vezes pedimos para o aluno produzir cartazes no dia do índio e no dia da abolição”. Demonstra- se com esse relato que não é trabalhado de forma consistente a se valer um aprendizado a fim de valorizar a herança índia-africana na cultura brasileira. Outro problema que aparece nos relatos é que os sistemas exigem muito do professor a apenas cumprir conteúdo que é focado na alfabetização e matemática e menos na cidadania e que até reconhecem a importância da temática, mas que não dá tempo de trabalhar. Outro problema é falta de capacitação, já que nem todas prefeituras se preocupam com tal prática e o baixo preço dos salários torna impeditiva uma pós-graduação na área. Os professores, que em sua formação não receberam preparo especial para o ensino da cultura africana $e$ suas reais influências para a formação da identidade do nosso país, entram em conflito quanto à melhor maneira de trabalhar essa temática na escola. Nesse sentido, este ponto pode ser um dos obstáculos estabelecidos com a lei 10639/03, porque nessa lei não há nenhuma menção de cursos para capacitação dos professores ou ainda a reestruturação das bases pedagógicas num movimento que resgate e ressalte a importância dessa cultura em sala de aula. Sendo assim, é primordial a preparação desses professores, principalmente os do ensino infantil onde se inicia o desenvolvimento humano e social das crianças; porque é durante a educação infantil que as crianças já começam a conhecer seu corpo, as diferenças e semelhanças entre os colegas do grupo escolhem com quem brincar e se relacionar na escola, tem suas preferências por brinquedos, e, no entanto é fundamental que o educador trabalhe em sala de aula questões sobre diferença e em especial as relacionadas as diferenças raciais, não só com as crianças, mas com as famílias e comunidade. 
O que se tem observado na maioria das vezes são esforços isolados de alguns professores incluírem nas atividades pedagógicas assuntos que valorizem o conhecimento de História da África junto aos alunos e a escola. No entanto, muitas vezes, a própria instituição não está engajada para promover o ensino voltado para a diminuição das desigualdades étnico-raciais. Isto só multiplica o preconceito. Preconceito é definido pelo sociólogo Nogueira como:

Considera-se como preconceito racial uma disposição (ou atitude) desfavorável, culturalmente condicionada, em relação aos membros de uma população, aos quais se têm como estigmatizados, seja devido à aparência, seja devido a toda ou parte da ascendência étnica que se lhes atribui ou reconhece.. (NOGUEIRA, 1985, p. 78-9)

Portanto o preconceito de qualquer espécie, em especial o racial, que ainda hoje é um dos mais presentes na sociedade, precisa ser muito bem delineado e muito bem trabalhado, e não somente com crianças e jovens, mas também com adultos, pois este assunto, não surgiu a pouco, mas já é um caso macróbio³.

Como, então, reverter esse quadro preconceituoso que prejudica a formação do verdadeiro cidadão e a educação de todos alunos, em especial os membros dos grupos étnicos, vítimas do preconceito e da discriminação racial? Não existem leis no mundo que sejam capazes de erradicar as atitudes preconceituosas existentes nas cabeças das pessoas, atitudes essas provenientes dos sistemas culturais de toda a sociedades humanas. No entanto, cremos que a educação é capaz de oferecer tanto aos jovens como aos adultos a possibilidade de questionar e desconstruir os mitos de superioridade e inferioridade entre grupos humanos que foram introjetados ${ }^{4}$ neles pela cultura racista na qual foram socializados, (MUNANGA-2005, p.17).

O racismo no Brasil é crime previsto na lei 7.716/1.989 e, além disso, em 2003 entrava em vigor a lei Io.639 que obriga a inserção, nos currículos das escolas públicas e particulares. Porém como era de se esperar, depois de muitos anos essa lei está longe de ser atendida, principalmente a pouca importância dada a este assunto pelas novas gerações, principalmente devido à educação atual, que é eurocêntrica, ou seja, influência culturalmente, economicamente, politicamente e socialmente, dificultando a inserção desta lei no ambiente escolar. O preconceito racial, portanto, está ligado a diversas vertentes, não sendo está somente pela raça, mas também por outas

\footnotetext{
${ }^{3}$ Macróbio: que ou aquele que chegou à idade muito avançada.

4 Introjetados: fazer com que alguém absorva ou interiorize alguma coisa: introjetava os saberes que aprendia.
} 
características, como social e econômica, sendo então o racismo considerado uma doutrina antropológica e política em alguns países.

Muitas vezes o assunto tratado de forma mecânica. Ao entrevistar muitas professoras oriundas de universidades $\mathrm{EaD}$, no interior de São Paulo, ao serem perguntados como tratavam a temática indígena e negra na sala de aula era a parecida com uma resposta exemplo que ora se seleciona: "as vezes pedimos para o aluno produzir cartazes no dia do índio e no dia da abolição”. Demonstra- se com esse relato que não é trabalhado de forma consistente a se valer um aprendizado a fim de valorizar a herança índia-africana na cultura brasileira.

Outro problema que aparece nos relatos é que os sistemas exigem muito do professor a apenas cumprir conteúdo que é focado na alfabetização e matemática e menos na cidadania e que até reconhecem a importância da temática, mas que não dá tempo de trabalhar. Outro problema é falta de capacitação, já que nem todas prefeituras se preocupam com tal prática e o baixo preço dos salários torna impeditiva uma pósgraduação na área.

O princípio da educação é a conscientização, não só dos alunos, mas de toda a sociedade em seus múltiplos aspectos. De nada adiantaria trabalhar com os alunos sem trabalhar na família. O trabalho com as famílias requer que as equipes de educadores trabalhem para compreendê-las e tê-las como parceiras, pois trabalhar a diversidade étnico-racial com as crianças e família em conjunto é primordial para um trabalho eficaz. Os pais devem ser informados sobre as atividades e participarem juntos trazendo informação sobre as culturas, porque toda informação é válida e rica para a construção pedagógica da criança, onde todas as aprendizagens e experiências pedagógicas necessitam ser envolventes e repletas de sentido. Para aprender as crianças devem ter seus desejos, suas vidas, suas histórias e suas culturas consideradas. Para que isso ocorra às práticas culturais dos grupos sociais devem servir como estudos para as crianças que frequentam o mesmo espaço da educação infantil.

Um problema sempre apontado é a herança religiosa dos pais dos professores e gestores. Ao se trabalhar certos aspectos da cultura africana, certos pais envoltos numa cultura neopentecostal entendem ser maligno aos seus filhos. Uma solução que encontramos numa escola foi trabalhar a partir dos mitos. O mito demonstra uma 
herança racial, pois mesmos esses pais de cultura neopentecostal não temem que os filhos trabalhem a mitologia grega ou egípcia, visto que são deuses brancos, mas temem a mitologia africana.

Os próprios praticantes de religiões indígenas não vêm problema em se tratar como mito, pois o mito não é mentira e sim um modo de transmitir lições e de poder de traduzir a realidade de um modo estético e que as pessoas assumem como verdade mais do que a ciência. Os mitos segundo Campbell, são as histórias que conduzem nossas vidas, "Mitos são pistas para as potencialidades espirituais da vida humana" (CAMPBELL, 2007, p. I4).

Assim desconstruir o preconceito familiar e atender uma necessidade escolar extra classe atender a comunidade ao entorno escolar na sua finalidade educativa. A escola é um lugar onde existem várias etnias. Cabe ao professor ter criatividade e saber trabalhar. A criança já vem de casa com uma "bagagem" de preconceito. Os pais desde pequenos educam para o preconceito mesmo inconscientemente. O preconceito está presente mesmo na hora de montar um grupo para realizar um trabalho escolar.

O espaço educativo deve ser planejado de forma a satisfazer as necessidades da criança, ou seja, tudo deverá estar acessível ao educando, desde objetos pessoais, assim como os brinquedos. Os ambientes de aprendizagem para a igualdade racial devem ser abertos às experiências infantis e possibilitar que as crianças expressem seu potencial, suas habilidades, e curiosidades e possam construir uma autoimagem positiva.

Além de trabalhar com aos alunos o princípio da educação é a conscientização de nada adiantaria trabalhar com os alunos sem trabalhar na família. O trabalho com as famílias requer que as equipes de educadores trabalhem para compreendê-las e têlas como parceiras, pois trabalhar a diversidade étnico-racial com as crianças e família em conjunto é primordial para um trabalho eficaz. Os pais devem ser informados sobre as atividades e participarem juntos trazendo informação sobre as culturas, porque toda informação é válida e rica para a construção pedagógica da criança, onde todas as aprendizagens e experiências pedagógicas necessitam ser envolventes e repletas de sentido. Para aprender as crianças devem ter seus desejos, suas vidas, suas histórias e suas culturas consideradas. Para que isso ocorra às práticas culturais dos grupos sociais 
devem servir como estudos para as crianças que frequentam o mesmo espaço da educação infantil.

Não há como negar a importância da legislação, mas ainda muito falta para sua aplicabilidade ou mesmo outras leis, para a nossa história e educação. Apesar das dificuldades e possíveis desvios na sua implementação, sem sombra de dúvida, a Lei é uma conquista e, servirá na construção de novas relações sociais. Sabemos que somente uma Lei não irá mudar a realidade do país, mas o silêncio que reinou durante décadas dentro da Escola sobre a questão do negro e índio, também não resultou em mudanças.

O nosso sistema educacional ainda está em fase de desenvolvimento, digase de passagem, em um estágio ainda prematuro, mas essas novas atividades e ideias finalmente estão se fazendo presentes, através de novos projetos e professores realmente valorizem esses conhecimentos e insiram em seus planos de aula despertando uma renovação de práticas educativas. É preciso desenvolver novos trabalhos com a participação de professores, capacitação para os docentes e cursos de formação continuada.

Contudo sem dúvidas nenhuma é preciso fazer com que as escolas avancem com relação a estratégias, ações, projetos e construam novas práticas pedagógicas, e novas posturas, visando a valorização da cultura negra, tendo como foco principal uma educação que contemple a igualdade racial, mostre, no mínimo desde a educação fundamental e infantil a importância das diferenças étnicas.

\section{UM POUCO DE MEMÓRIA E HISTÓRIA}

A ideia de rupturas e permanências é uma perspectiva teórica de compreensão histórica do mundo. É por meio dessa compreensão que se pode conhecer e compreender narrativas a respeito das relações humanas no tempo e espaço. No cotidiano podemos notar algumas rupturas e permanências com relação a vários períodos históricos, como, por exemplo, o período medieval: antes comum, hoje já não se vê a prática de caça às bruxas ou condenação de hereges em praça pública, o que representa uma ruptura. No entanto, ainda hoje, igrejas cristãs, sobretudo pentecostais, 
condenam as práticas de saberes populares de outras religiões ${ }^{5}$, que poderiam ser, na era medieval, confundidas com práticas de bruxaria, isso é, permanência.

A dialetização do método, proposta por Lefebvre(1983), impõe a consideração de duas dimensões temporais entrelaçadas: a dimensão horizontal ou sincrônica, que permite estudar a inserção do objeto de estudo no contexto de sua época, e a dimensão vertical ou diacrônica, que estuda a coexistência de processos históricos diferentemente datados. O conhecimento deve ser submetido a um "movimento de duplo sentido: regressivo (do virtual ao atual, do atual ao passado) e progressivo (do superado e do terminado, ao movimento que determina aquela conclusão e que anuncia e faz surgir algo novo)" (LEFEBVRE, 1983, p. 30). A aplicação do método regressivo-progressivo pressupõe uma abertura metodológica de entender que determinados processos culturais são plenos de imbricações entre passado e presente. Assim, a história não deveria ser vista como uma sucessão progressista de fatos ocorridos, mas como processos articulados no quadro de forças em conjunção seletiva existente no presente (SANTOS, 1997, p. 265). De acordo com Lefebvre (1983, p. 231): “evitar a confusão numa continuidade ilusória, bem como as separações ou descontinuidades absolutas, esta é a regra metodológica”.

\section{A IDENTIDADE INDÍGENA}

A identidade do indígena se encontra entre fronteiras culturais do conservacionismo ascético intramundano e da sedução pela mercadoria ou rompimento do tradicionalismo em identidades aparentemente contraditórias - uma construção de uma identidade complexa.

A construção da identidade, sobretudo da religiosa, não mais encontra padrões uniformes na pós-modernidade, que é marcada pela falência das metanarrativas. Cada sujeito dará sentido à sua identidade conforme o sentimento de pertencimento que mantém, porém, essa relação fica complicada em meio a uma instituição que prega valores comportamentais mais ou menos padronizados. Vale também concordar com Cabral e Lourenço (1993, p. I62), que, num estudo em Macau, território de intensa

\footnotetext{
5 Por exemplo, há tremenda perseguição e disputa do campo religioso entre igreja evangélicas e igrejas de matriz afro, sendo que as a primeiras acusam as segundas de bruxaria.
} 
circulação de grupos de diferentes origens, observaram que "Perante situações muito semelhantes, as opções identitárias de cada pessoa podem ser radicalmente diferentes". Para esses autores, isso ocorre porque as pessoas optam por "[...] posicionamentos distintos por razões que só o seu passado pessoal e psicológico poderá determinar”. Sendo uma igreja assembleiana brasileira um território também de grande afluxo cultural, e que assumiu ao longo de sua história valores suecos e norte-americanos, entre outros, institucionais, vale o trabalho dos pesquisadores macauenses.

Analisando essa questão, define Pesavento (2020. p.36.):

[...] fronteiras culturais remetem à vivência, às sociedades, às formas de pensar intercambiáveis, aos ethos, valores, significados contidos nas coisas, palavras, gestos, ritos, comportamentos e ideias. [...], a fronteira cultural aponta para a forma pela qual os homens investem no mundo, conferindo sentidos de reconhecimento. A fronteira cultural é trânsito e passagem, que ultrapassa os próprios limites que fixa, ela proporciona o surgimento de algo novo e diferente, possibilitado pela situação exemplar do contato, da mistura, da troca, do hibridismo, da mestiçagem cultural.

As autoidentificações culturais são partes de um processo caótico e complexo, tanto na forma quanto no conteúdo. Dentro do grupo, os membros ocultam e negociam as significações identitárias de seus bens simbólicos, conforme a teoria bourdiana, de modo que se situem como melhor lhes convier nas relações. Desde Barth, sabe-se que as fronteiras culturais podem se tornar permeáveis ou desaparecer, levando à fusão de culturas previamente separadas.

A cultura e, portanto, a identidade indígena está separada por valores ora anacrônicos, ora sincrônicos, em meio a urbanidade pós-moderna, porém aos poucos muda e adapta-se, aceitando valores e estéticas dessa urbanidade. Esse movimento pode fazer emergir novas fronteiras culturais ou ocasionar a mudança de lugar das velhas fronteiras, possibilitando o surgimento de novas formas de adaptação cultural ou a reformulação das antigas.

A memória pode ser encarada não somente como uma ferramenta de guardar dados mnemônicos, mas, sobretudo, como uma capacidade de (re)significação das coisas e de si mesmo (RICOEUR, 2007, p. 40). Ela se manifesta em uma crença coerente com um comportamento social que constitui a sua identidade diferenciada de qualquer outro grupo. Essa identidade faz-se transmissível não exatamente por meio de um discurso ou de uma recuperação de memória, mas, sim, de uma imitação 
desconexa da história formal, feita por outros membros mais antigos do grupo, que se manifesta coletivamente. Por convivência e imitação, adquire os hábitos, as práticas cotidianas, a linguagem, os costumes daquele grupo, assumindo assim uma disposição bourdiana de habitus daquele grupo. Aqui entende-se habitus como:

[...] um sistema de disposições duráveis e transponíveis que, integrando todas as experiências passadas, funciona a cada momento como uma matriz de percepções, de apreciações e de ações - e torna possível a realização de tarefas infinitamente diferenciadas, graças às transferências analógicas de esquemas [...] (BOURDIEU, 1987).

A crise da identidade indígena é provocada em sua forma mais pura pelo capitalismo pós moderno - Assim, o capitalismo e a técnica com sua máquina de miserabilidade assim como sua razão produz monstros para citar a famosa obra de Goya. Esses monstros são produzidos em uma estética de morte, corrupção, invencibilidade e domínio, ou seja, a própria essência da monstruosidade. Ainda o capitalismo moderno, ao se opor a certos valores, produz outros monstros como o fundamentalismo, o crescimento desenfreado das cidades e o aumento de violência em face à incompetência dos governos de controlá-la.

O livro mostra isso, sobretudo no choque de cultura do capítulo em que se

encontra na aldeia o menino branco. É patente a descrição do choque e desrespeito que o visitante demonstra pelos seus receptores. Esse choque não está o livro à toa, demonstra o conflito e desrespeito que o branco sempre sentiu, mas a criança, demonstra de forma mais pura.

\section{SOBRE O LIVRO EM SI}

Como dito pelo próprio autor é uma homenagem à memória das brincadeiras e caçadas de tatus que não ocorrem mais, segundo o próprio na introdução(OLIVEIRA, $2020 \mathrm{~s} / \mathrm{p})$ :

\footnotetext{
Hoje já não é tão comum vê-los praticarem atividades como as caças tradicionais. A caça de tatu já não é mais uma aventura que instiga o extinto caçador dos Kunumigwé da aldeia, porque, atualmente, a tecnologia nãoindígena se tornou muito mais atraente... Por exemplo: um dos motivos pelos os quais já não se realiza mais a caça de tatu, é a preservação dos animais; outro é a perda do paladar por carne exóticas, e, sendo assim, não se pode julgar radicalmente os Kunumingwé que aceitar que os tempos mudaram, e a tendência é mudar cada vez mais.
} 
Os Kunumingwé ou jovens, caçar tatu seria a preparação para ser grande caçador em outros tempos, era também uma brincadeira, um jogo já que o lúdico faz parte do ser humano. Huizinga (2007) define o lúdico como:

\begin{abstract}
Uma atividade livre, conscientemente não séria, com espaços, tempos e regras fora do habito, sendo exterior à vida habitual, sem interesse material, na qual não se poderia obter lucro. O lúdico, por ser ricamente simbólico, abre caminho para as representações da vida humana, como também para a modificação destas. No estado lúdico se incorpora os valores e significados da sociedade. E possibilita a entrada na cultura, numa cultura particular, tal como ela existe num dado momento, mas com todo seu peso histórico." (HUIZINGA, 2007, p. 82).
\end{abstract}

O jovem entra em contato com o sagrado, já que a atividade de caça em si era sagrada, através do lúdico e separa o que há de profano em si, paradoxalmente atuando como profano. Os rituais de culto hoje, através de forma lúdica, sacralizam as formas profanas de diversão e, ao mesmo tempo, profanam as formas de adoração, cuja função fortalece ao agrupamento dos jovens em seus rituais de pertença. Segundo Durkheim (200I) o sagrado favorece a coesão social.

Analisando uma fala preocupante acima "a tecnologia não-indígena se tornou muito mais atraente $\mathrm{O}$ rádio e a TV foram os primeiros a chegar; então, veio o celular e suas múltiplas facetas... depois, o computador e o videogame chegaram também" (introdução, $2020 \mathrm{~s} / \mathrm{p}$ ), é comum ouvir dos alunos brancos que se o índio tem celular não é mais índio, ora, não é a tecnologia que perfaz a identidade, sobretudo uma tecnologia empurrada pelo próprio branco em qualquer zona rural, issodeve ser tratado em sala de aula. Segundo Hall (2005), a identidade plenamente segura e unificada é uma fantasia; o que há são identidades pluralmente formadas a partir de contextos diversos e temporários.

Barth (1989), tratando da identidade, traz à tona o que chama de "emblemas de diferença": a história pessoal e comunitária de cada um traz a assunção de uma diferença com outras alteridades. As pessoas (indivíduos e grupos) selecionam do seu repertório cultural (vestimenta, língua, moradia, etc.) algum signo (traço diacrítico) para delimitar-se de outros e para exibir uma identidade comum. 


\section{CONCLUINDO}

O livro é de e uma linguagem simples, perfeitamente adequada a depender do diagnóstico da turma, a ser trabalhado a partir do quarto ano do ensino fundamental com os alunos já lendo, não impendido que o professor faça roda de leitura nos anos anteriores.

É cheio de historias e linguagens típicas por exemplo: “...Rio Batalha pertence a uma Tekoá de etnia Terena, a Tekoá Kopenoti. Os Terena vieram se juntar aos Guarani no estado Grosso do Sul, região de Aquidauana, Miranda, entre outras...(OLIVEIRA, 2020, p. 4I)

Dotado de um glossário o professor poderá estar levando uma autentica memoria indígena para dentro da sala de aula que pode discutir, recomenda-se como avalição a roda de conversa junto com outros instrumentos que o professor queira.

Cabe ao professor ter criatividade e saber trabalhar. A criança já vem de casa com uma "bagagem" de preconceito. Os pais desde pequenos educam para o preconceito mesmo inconscientemente. O preconceito está presente mesmo na hora de montar um grupo para realizar um trabalho escolar.

Uma técnica para trabalhar com alunos e família é a Proposta de atividade história de racismo com os avós. Poderia voltar nos tempos dos avós que contavam histórias para os filhos, pais e netos. Seria aplicar tarefas e questionários com os pais e avós como tarefa para relatar perante a sala de aula e discutir com os alunos as impressões tantas negativas como positivas e verificar a impressões indígenas e se há alguma que tenham alguma intersecção com o livro .

Outra atividade seria através de músicas. A música tem papel preponderante na educação, apesar da LDB(BRASIL, 1996), preconizar a importância da música, nem sempre há essa possibilidade. O despreparado do professor, a falta de professor específico e alto custo dos materiais musicais dificulta a aplicação. Mesmo quando tais barreiras são superadas há pouco interesse ou mesmo preparo para a musicalização índio e negra. Apresentar variedade de músicas, histórias, brincadeiras, é uma forma de implementar a legislação e trazer músicas indígenas típicas pois "quem não se vê" e não se reconhece, não se identifica; e quem não se identifica tem auto-estima baixa, não se ama e se desinteressa por tudo que o representa. 
Outra atividade seria uma simulação de "caça ao tatu" e a montagem de tatus de material reciclável para depois fazer o jogo da caça.

Assim espera-se que se minore o preconceito, trazendo a voz indígena para a sala de aula através do livro.

\section{REFERENCIAS}

BRASIL, Lei de Diretrizes e Bases da educação. Lei no 9.394/96, de 20 de dezembro de 1996.

. Lei Federal n ${ }^{\circ}$ 10.639/o3 Diretrizes Curriculares Nacionais para a Educação das Relações Étnico-Raciais e para o Ensino de História e Cultura Afro-Brasileiras e Africanas. Brasília, 2004: Conselho Nacional de Educação.

BARTH, Fredrik. The analysis of culture in complex societies. Ethnos, 54(3-4): 120-142, 1989.

BOURDIEU, Pierre. A economia das trocas simbólicas. São Paulo: Perspectiva, 1987

CAMPBELL, J. Mitos, sonhos e religião. Trad. Ângela Lobo de Andrade e Bali Lobo de Andrade. Rio de Janeiro: Ediouro, 20oI.

DURKHEIM, É. As formas elementares da vida religiosa. São Paulo: Paulus, 200 .

HALL, Stuart. A identidade cultural na pós-modernidade. ı. ed. Rio de janeiro: Dp\&a, memória americana. São Paulo, Annablume, 2005.

HUIZINGA, Johan. Homo Ludens. $5^{\circ}$ ed. São Paulo, SP: Perspectiva, 2007.

LEFEBVRE, H. Lógica formal, lógica dialética. Rio de Janeiro: Civilização Brasileira, I983.

OLIVEIRA, Tiago de. Quando eu caçava tatu e outros bichos. / Tiago de OliveiraSão Paulo (SP): 2020 .

PESAVENTO, Sandra Jatahy. Além das Fronteiras. IN: Martins, Maria Helena (Org.) Fronteiras Culturais. Brasil-Uruguai-Argentina. São Paulo-SP: Ateliê Editorial, 2002,.

RICOEUR, P. A memória, a história, o esquecimento. Campinas: Unicamp. 2007.

SANTOS, B. de S. Pela mão de Alice: o social e o político na transição pós-moderna. São Paulo: Cortez, 1997. 